\title{
Design and Performance of PV Dust Cleaning System in Medina Region
}

\author{
Khaled S. Al Qdah, Saleh A. Abdulqadir, Nawaf Y. Al Harbi, Abdullah Z. Soqyyah, Kamal J. Isa, \\ Mohmmed Y. Alharbi, Nasser M. Binsaad
}

Mechanical Engineering Dept. College of Engineering, Taibah University, Madinah, KSA

Email: dr.khaled_qdah@yahoo.com

How to cite this paper: Al Qdah, K.S., Abdulqadir, S.A., Al Harbi, N.Y., Soqyyah, A.Z., Isa, K.J., Alharbi, M.Y. and Binsaad, N.M. (2019) Design and Performance of PV Dust Cleaning System in Medina Region. Journal of Power and Energy Engineering, 7, 1-14.

https://doi.org/10.4236/jpee.2019.711001

Received: September 23, 2019

Accepted: November 9, 2019

Published: November 12, 2019

Copyright $\odot 2019$ by author(s) and Scientific Research Publishing Inc. This work is licensed under the Creative Commons Attribution International License (CC BY 4.0).

http://creativecommons.org/licenses/by/4.0/

\begin{abstract}
This work aims to design a cleaning system for the solar PV panels under Medina climatic conditions. This system powered by the PV module itself. Full cleaning system has been designed and tested utilizing a wiper and water jet to remove the accumulated dust and other dirt from solar panels surface. The proposed cleaning system can be worked for long time efficiently. All the strength system components were examined and found to be stable and reliable. Also, the performance of cleaning system evaluated and comparison between the clean and dusty module performance has been conducted. The system performance has been evaluated for both clean and dusty panel at variable inputs of solar radiation. At input power of $805 \mathrm{~W} / \mathrm{m}^{2}$, the efficiency found to be $13.78 \%$ for the cleaning panel and $9 \%$ for dusty panel, whereas at the input power of $460 \mathrm{~W} / \mathrm{m}^{2}$, the estimated efficiency was $12.6 \%$ and $7.3 \%$ for clean and dusty panel respectively. Significant reduction in the efficiency has been reported as $35 \%$ and $42 \%$ for both cases. Therefore, the present work can be considering as a promising and efficient system to solve the problem of poor performance of the photovoltaic cells in areas that experience dusty environment and external pollutants. In addition, it is safe clean and economic system.
\end{abstract}

\section{Keywords}

Dust, Performance, Photovoltaic, Solar Radiation, Climatic Conditions

\section{Introduction}

Saudi Arabia has one of the world's highest solar irradiation in the world. The country is strategically located near the Sun Belt, in addition to open and empty desert that may accommodate infrastructure for solar power systems [1]. Medina, one of the most important cities in Saudi Arabia that lies in the west region, 
has witnessed a high energy demand last ten years. Therefore, it is necessary to seek for non-conventional energy resources like renewable energy. Solar energy is one of the most promising sources to replace the dependency on the conventional energy sources. Solar Photovoltaic (PV) panels convert the sunlight to electrical energy. The PV cells made of different semiconductor materials connected together in the form of chains to form larger units known as modules or panels [2]. The PV panels are working on an atomic scale to produce the power, the installation, maintenance time and costs can play a significant role in the efficiency of the energy that comes from the PV panel. The problem in the PV systems is that these panels get dirty over time. Dust accumulation on the PV panel surface leads to a reduction in energy output and decreases the efficiency of the solar system. If the panels leave without cleaning, the output power even more, therefore cleaning the photovoltaic panels frequently is essential to get the necessary power output from these panels.

Cleaning the solar panels passed through several stages starting from using workers to do manual cleaning. Although many companies provide a cleaning service to regain the desired potential of the panel, the services they offer are traditional ways to clean and very expensive. The average cleaning price per panel is around 20 SR per panel for one-time cleaning. Some companies provide a monthly cleaning service, and it costs 43 SR per panel a month for two meters by one-meter panel.

Clearly, the PV panels in Medina region are needed to be cleaned regularly due to the dusty weather, and for that, the process will be very costly. Some companies have produced machines to clean solar panels, while other companies have developed smart robots for this purpose.

Medina region is classified as a desert environment. Being under this weather condition will cause the dust and sand to accumulate on exposed surface of the solar panel. Dust and other external pollutants can block the photons form the solar panel which will effectively reduce the output power. In this work, designing and manufacturing a mechanism to clean the PV system has been carried out in Medina city which exposed to dust during the windy days. Also, the PV panels can be exposed to other contaminations from trees, birds' dropping and other pollutants from the surrounding environment like smoke, building constructions. All these contaminants will be accumulated on the surface of the panel which leads to a reduction in the absorptivity of this surface for solar radiation. Those types of issues have limited the solar from becoming a primary utilized source of energy. In addition, a film of dust or a microscopic debris can block the photons from the panel, and that can affect the productivity of the solar panel [3]. Cleanliness and clarity must be kept throughout every centimeter of the PV panel to produce the desired power. Dust deposition in most parts of the kingdom of Saudi Arabia has an impact on solar panel energy production and use. According to an article published by The Economist, the Gulf region has the most toxic air in the world. The writer refers to the World Health Organization which claims that the region's poisonous atmosphere comes from the 
dust made of sand kicked by windstorms and movements of construction [4].

Solar panels can lose $36 \%$ efficiency in just one month, $60 \%$ efficiency in two months, and after one year has no energy production at all, for this reason an automated cleaning system must be designed and utilized [3]. Due to these high-efficiency losses, scientists and researcher conducted many research to overcome the problems and suggest a solution to use solar panels in extreme climates and the most available studies presented by Mohamed and Hasan (2012) [3] studied the effect of dust accumulation on the performance of photovoltaic solar modules in Sahara environment. They investigated a framework of weekly cleaning on PV modules array throughout the period from February to May. The results indicated a significant gradual decrease of power, so frequent weekly water washing maintaining performance losses between (2\% - 2.5\%). Mani, Pillai (2010) [5] studied the impact of dust on solar photovoltaic (PV) performance. They found that the dust factor significantly influences the performance of the PV installations. And they recommend a minimum weekly cleaning for PV. A. Ibrahim (2011) [6] investigated the effect of shadow and dust on the performance of silicon solar cell. He found that from $5 \%$ to $15 \%$ reduction in peak power has been observed by various climatic conditions, especially accumulated dust. Goossens, Van Kerschaever (1999) [7] investigated the effect of dust deposition on photovoltaic solar cells performance. Four tests under variable wind velocities and dust concentrations. They found that the decline in PV cell performance due to dust accumulation is larger as wind speed increases. Plaza et al. (2015) [8] studied the performance and improvement techniques for photovoltaic systems in Qatar. They stated that the environmental conditions were high ambient temperatures, a dusty atmosphere, and water scarcity affect the performance of PV panels. Sharma et al. [9] designed a flexible electrodynamic screen to protect the solar cell on Martian explorer based on travel-wave field technology. They proposed a device system that moves on the surface of the solar panel and cleaned the surface with the help of a brush. Sayyah et al., 2013 [10] reported the costs and benefits of three current methods of cleaning solar panels. These methods include natural cleaning through rain and snowfall, manual cleaning, and cleaning by an electrodynamic system (EDS). Burton et al. [11] investigated the effects of different types of dirt on solar panel efficiency. Various types and colors of soil were tested with the emphasis on targeting dirt compositions that are found in the southwest of the United States. Verma and Singhal (2015) [12] conducted the performance parameters affect the optimization and performance in large scale grid solar PV plant such as radiation, temperature, and other climate conditions, design parameters. Over 25 years of time span. Shaharin et al. 2011 [13] carried out an experimental study on the effects of dust accumulation on the performance of solar PV panels. Experiments were conducted using dust particles on solar panels with a constant-power light source, the reported results show that the dust accumulation may reduce the efficiency to 50\%. Ali, H. M., et al. (2017) [14] investigated the effect of dust deposited on the surface of two different types of photovoltaic modules (monocrys- 
talline silicon and polycrystalline silicon) for Texila, Pakistan for the measurement for three months.

From the previous studies, it can be seen that intensive work has been done but there is a lack of studies in Saudi Arabia and very little work has been conducted. The effect of dust on the performance of PV panels in Saudi Arabia especially in Medina region can be considered as a motivation to perform this work. Also these studies verified that the traditional way is mostly expensive, and it consumes human resources and time to be done. Besides, the modern existing systems are complicated and costly.

\section{Material and Method}

The objective of this work is to design and fabricate PV cleaning system that can work for long time with a minor loss of efficiency, to achieve this, a detail design analysis will be conducted The performance of the implemented design has been tested and evaluated under Medina climatic conditions. The design methodology and material are as follow:

\subsection{Solar Panel Specifications}

The panel used in this work could generate an output power comparing to close size approximately. Table 1 summarized the technical specifications of the selected panel. The inclination angle of the solar panel must be specified firstly because it is important to optimize the output energy from the panels by applying the solar beam perpendicular to the surface. The latitude of Medina is $24^{\circ} 28^{\prime} 7^{\prime \prime}$ and the optimum tilt angle for Medina is around $22^{\circ}$ for a fixed tilt angle solar panels [15].

\subsection{The Cleaning System Design}

The selected design components for the cleaning system containing motors, pump, water jets, and the cleaning rod as shown in Figure 1. This system will move horizontally with a speed of $0.13 \mathrm{~m} / \mathrm{s}$. Assuming the cleaning time 15 seconds and 2 meters as a travelled distance. This design was chosen because it is cheaper in terms of maintenance, and it is more applicable for several PV panels. Unlike the other designs where the cleaning is too low. The frame was designed to withstand all the components. The material used for the structure is aluminum to decrease the weight of frame. Aluminum is also resist the corrosion.

The frame was designed and checked from stress and stability point of views and found to be safe and stable. The mass of the selected panel $\mathrm{m}$ is about $20 \mathrm{~kg}$. and the load on every Column

$$
\begin{aligned}
W & =20 \div 4=5 \mathrm{~kg} \\
\sigma_{\text {compresion }}=\frac{W}{A} & =\frac{5 \times 10}{\left[(40 \times 40)-(36)^{2}\right]} \quad[16]
\end{aligned}
$$

where $\sigma_{c}$ is the compression stress and $A$ is the cross sectional area. 
Table 1. Selected solar panel specification.

\begin{tabular}{cc}
\hline Maximum power & $200 \mathrm{~W}$ \\
\hline Module efficiency (Max) & $15.72 \%$ \\
Front surface & Anti-Reflective coated tempered $4 \mathrm{~mm}$ glass \\
Module dimensions & $1498 \mathrm{~mm} \times 680 \mathrm{~mm} \times 35 \mathrm{~mm}$ \\
Module weight & $12.6 \mathrm{~kg}$ \\
Operating temperature range & $40^{\circ} \mathrm{C}$ to $85^{\circ} \mathrm{C}$ \\
\hline
\end{tabular}

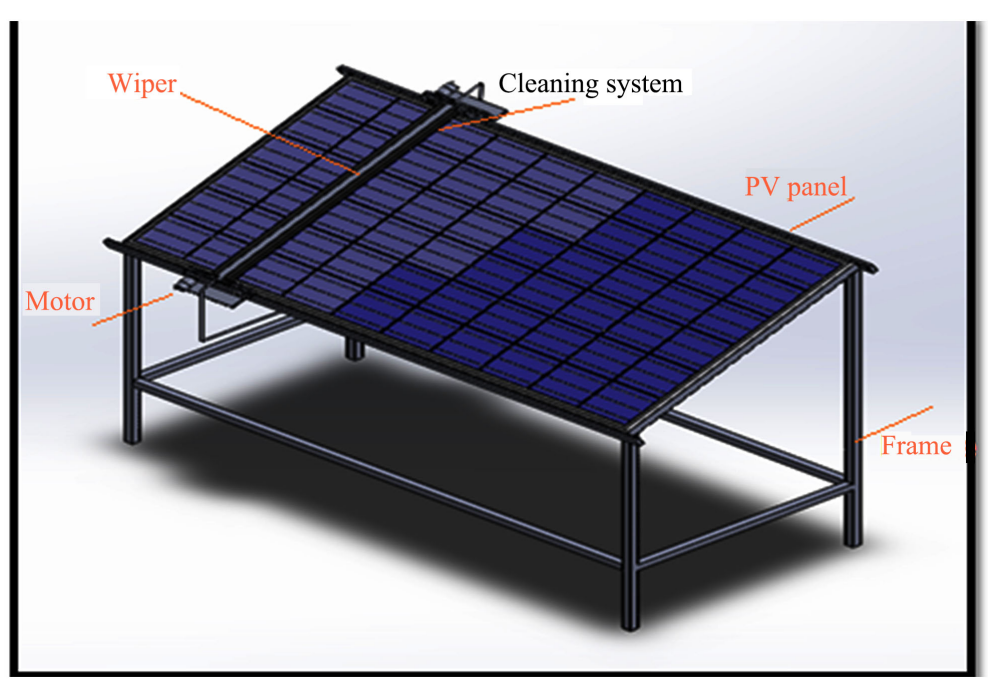

Figure 1. Selected design for PV cleaning system.

$$
\begin{gathered}
\sigma_{c}=\frac{50}{304}= \\
\sigma_{c} \leq \frac{S y}{F . S .}
\end{gathered}
$$

where $S y$ is the yield strength and F.S. is the factor of safety [16].

$$
0.165 \leq \frac{145}{F . S} \gg \text { F.S. }=304.7
$$

No compression will happen since the load is not much.

$$
F_{\text {Euler }}=\frac{\pi^{2} E I}{L_{\text {eff }}^{2}} \geq F_{\text {acting }}
$$

where $E$ is the modulous of elasticity, $I$ is the moment of area and $L_{\text {eff }}$ is the length when buchling hppens.

$$
\begin{gathered}
I=\frac{1}{12}\left[\left(40 \times 10^{-3}\right)^{4}-\left(36 \times 10^{-3}\right)^{4}\right]=7.34 \times 10^{-8} \mathrm{~m}^{4} \\
F_{\text {Euler }}=\frac{\pi^{2} \times 6.9 \times 10^{10} \times 7.34 \times 10^{-8}}{(0.5 \times L)^{2}} \geq 50 \mathrm{~N} \\
L=1.55 \mathrm{~m}>1 \mathrm{~m}
\end{gathered}
$$


The column will buckle when the length exceeds $1.55 \mathrm{~m}$. For our design, which is $1 \mathrm{~m}$, there will be no buckling and it will be stable.

\subsection{Electric Motor}

The function of the motor is to move the cleaning tool (wiper and water jet) on the surface of the solar panels back and forth by the wheels on both sides of the cleaning tool. Figure 2 shows the selected motor used to move the cleaning elements.

Motor power consumption

$$
\text { Power }=T \omega
$$

where $T$ is the Torque and $\omega$ is the angular velocity.

$$
\omega=\frac{2 \pi n}{60}
$$

where $n$ is the revolutions per minute

From motor specification $T=12 \mathrm{~kg} \cdot \mathrm{cm}=1.176 \mathrm{~N} \cdot \mathrm{m}$

$$
\begin{gathered}
n=30 \mathrm{rpm} \gg \omega=\frac{2 \pi \times 30}{60}=3.14 \mathrm{rad} / \mathrm{s} \\
\text { Power }=1.176 \times 3.14=3.7 \text { Watts }
\end{gathered}
$$

We have two motors and the total Power $=2 \times 3.7=7.4$ Watts

\subsection{The Wiper}

The system will clean the accumulated dust by a sponge that is attached to a rod designed to be over the panel as it shown in Figure 3. The weight of the rod and the electrical motor are creating a normal force on the PV panel. This normal force will cause a frictional force against the movement of the system. This effect will help the wiper to clean the cell.

The torque required to move the carriage is equal to the torque that is needed to overcome the friction force between the wiper and the surface of the panel. As shown in the free body diagram in Figure 3, the weight of the wiper is about 30 $\mathrm{N}$ and assuming a friction coefficient between the wiper and the surface $\mu=0.3$

$$
F_{f}=0.3 \times 30=9 \mathrm{~N} \approx 10 \mathrm{~N}
$$

where $F_{f}$ is the friction force

Also, assuming a cleaning time approximately 15 seconds and the wiper travel distance is $2 \mathrm{~m}$. Therefore, the velocity $(v)=\frac{2}{15}=0.13 \mathrm{~m} / \mathrm{s}$. Figure 4 displays the size of the wiper rotating wheel use to move the cleaning system assembly along the panel. The outside diameter of the wheel is $40 \mathrm{~mm}$.

$$
\begin{gathered}
\varnothing=40 \mathrm{~mm}, \quad R=20 \mathrm{~mm} \\
\omega=\frac{v}{R}=\frac{0.13}{20 \times 10^{-3}}=6.5 \mathrm{rad} / \mathrm{s} \\
\mathrm{RPM}=6.5 / \frac{2 \pi}{60}=30.07 \mathrm{RPM}
\end{gathered}
$$




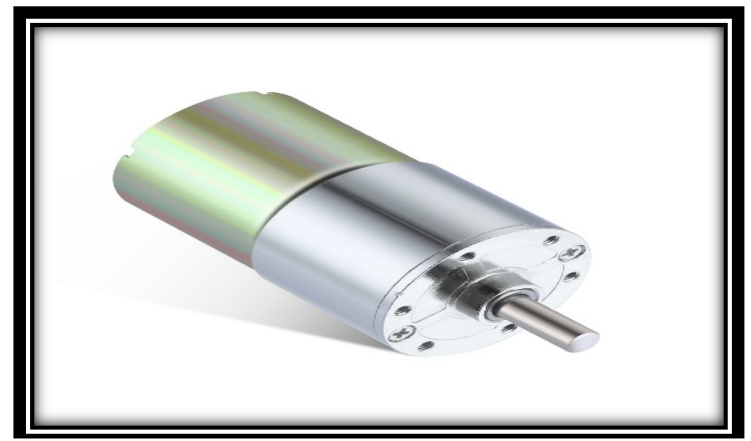

Figure 2. $12 \mathrm{~V} \mathrm{DC}$ motor used to move the wiper and water jet.

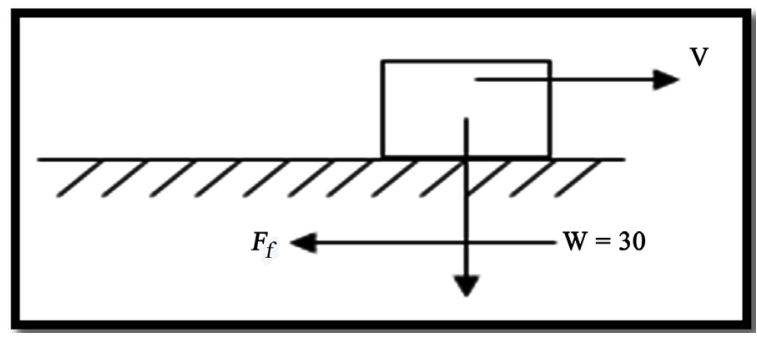

Figure 3. The wiper used to clean the panel surface.

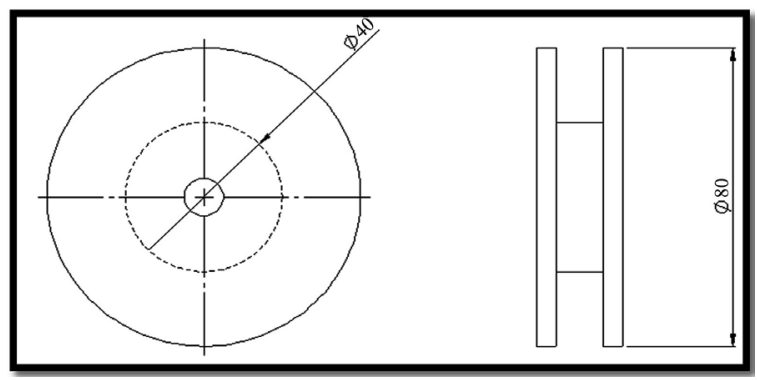

Figure 4. Wiper rotating wheel.

\subsection{Water Pump}

The function of the water pump is to supply the system with the necessary quantity of water to the desired design. This can be achieved by sucking the water from the tank then deliver it to the sprinkler. The working principle of this pump is to deliver water from low-pressure head to high and increase the rate of fluid flow. To accomplish the cleaning process efficiently and removing all type of dust and other deposits on the panel surface, a symmetrical water distribution on the surface of solar panels is needed. The selected optimum pump for this design is shown in Figure 5.

To estimate the required pumping power, assuming water flow rate to be

$$
\dot{Q}=2 \mathrm{~L} / \min
$$

$\dot{Q}=2 \times 10^{-3} / 60=3.3 \times 10^{-5} \mathrm{~m}^{3} / \mathrm{s}$. Assuming water pressure $=1 \mathrm{bar}=1=1 \times$ $10^{5} \mathrm{~Pa}$

Pumping Power $=\dot{Q} \times P=3.3 \times 10^{-5} \times 1 \times 10^{5}=3.3 \mathrm{Watt}$ 


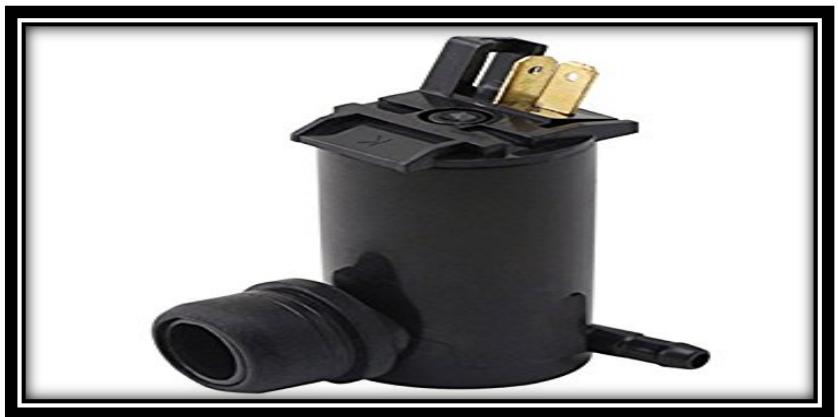

Figure 5. DC $12 \mathrm{~V}$ high pressure water pump.

$$
\text { Power }_{\text {motor }}=\frac{\text { Power }_{\text {pump }}}{\eta_{\text {pump }}}=\frac{3.3}{0.5}=6.7 \mathrm{~W}
$$

The pumps have multiple types according to their use, and a small pump that requires a low energy is enough. Total power consumption by the pump and two motors

$$
P=7.4+6.7=14.1 \text { Watts }
$$

Of course, there is a loss during the installation of any electrical system, and losses may reach up to $30 \%$ due to the conductivity and quality of the wires and the resistance of batteries used as well as the efficiency of solar panels. The PV module used in this investigation will provide the necessary power for the pump and motors. After that, the cleaning system of wiper, rotating wheels and connecting link were assembled as shown in Figure 6. The connecting link is manufactured from aluminum. The chosen rubber material used under the link is to give flexibility and to let the wiper to be moving easily and decrease the load on the motor. The wiper provided with the two nozzles or water jet to spray the water on the panel in front of the wiper. The designed and manufactured system is then assembled with the motor, wheels, shafts, nozzles and the link as it clears in Figure 6 below.

\section{Results and Discussion}

After the full cleaning system assembled and installed on the PV panel, the strength test has been performed to check the reliability and stability of the system. The following results were recorded for each component

\section{Stress Analysis Using the SOLIDWORKS Software}

The strength analysis of the components and frame shows the ability of the materials selected and the design to withstand the panel weight with the cleaning system without failure. The reported results show that all elements can carry more than 3 - 4 times the amount of load without any damage. Figure 7 shows the stresses on the coupling system which represent one of the important component subjected to load. Figure 8 also shows the stresses analysis for the link connected the two rotating wheels from each side. 


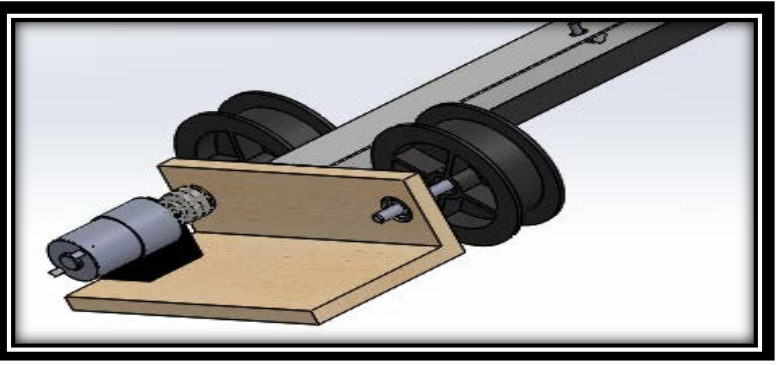

Figure 6. The full cleaning system after assembly.

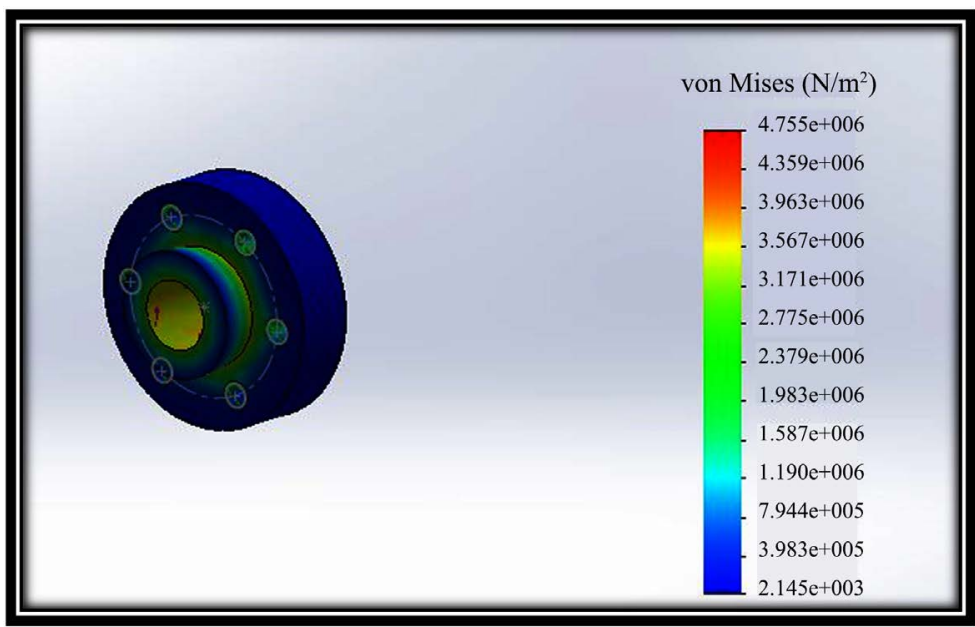

Figure 7. Stress analysis for the coupling system.

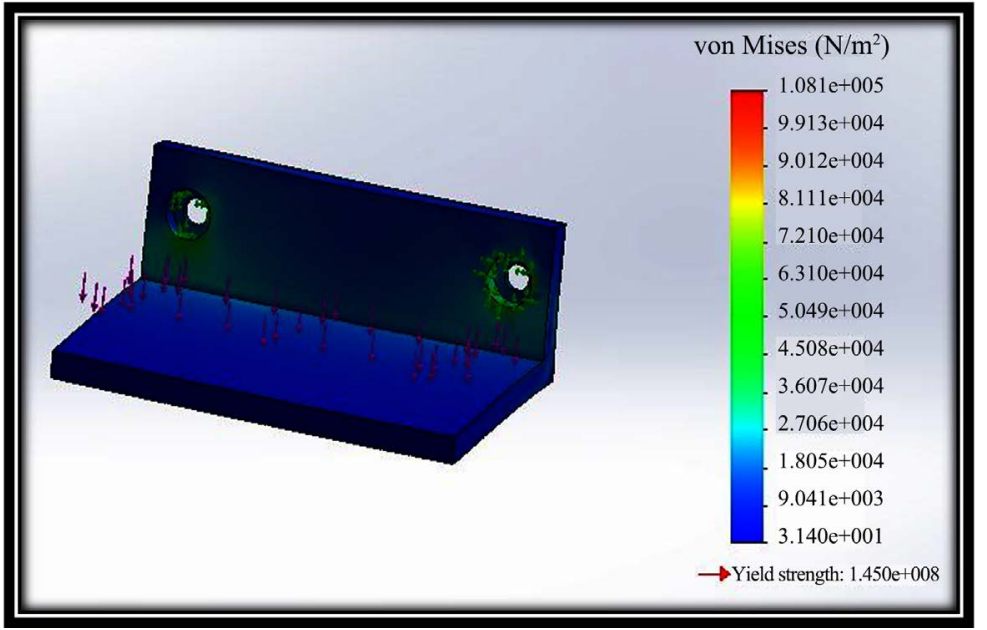

Figure 8. Stress analysis results for the link connected the main cleaning components.

Figure 9 shows the stress concentration on the main frame that carrying the PV panel in addition to the cleaning system, from the figure it can be seen the designed frame can withstand the components.

The actual product is shown in Figure 10. This system can be easily modified according to any PV specifications. In other words, setting up the solar PV can be challenging since the coverage area is always varies from one location to 
another. That means the solar panel can be changed so a new frame and links where replaced to fit the dimensions of the new panel. The friction between the tire and the panel surface was not enough and caused slipping sometimes, so a fabric with very high friction where used to increase the friction coefficient to prevent any slipping for the tiers.

The performance of the actual system has been tested and evaluated. Comparison between the performance of cleaning and dusty PV panels was conducted in Medina in clear sky day at different time. The system inputs and outputs were measure and recorded a long the day. The input which is the intensity of solar radiation was measured and found to be $460 \mathrm{~W} / \mathrm{m}^{2}$ at 10:00am and $805 \mathrm{~W} / \mathrm{m}^{2}$ 12.00 noon with the help of data logging Solar Power Meter model TES 132. The PV output was measured with the help of the solar module measurement unit model ET 250 proposed by GUNT as shown in Figure 11. The measuring unit allows measurement of current with the help of variable resistance, voltage solar radiation and temperature. The results can be observed on the display elements of the measuring unit with the correction factor for using direct solar radiation or illuminance.

Table 2 summarizes the measured values and calculated electric power for both the connected cleaning and dusty module. Then the current-voltage characteristic curve can be plotted for both cleaning and dusty module at variable input which is the solar radiation.

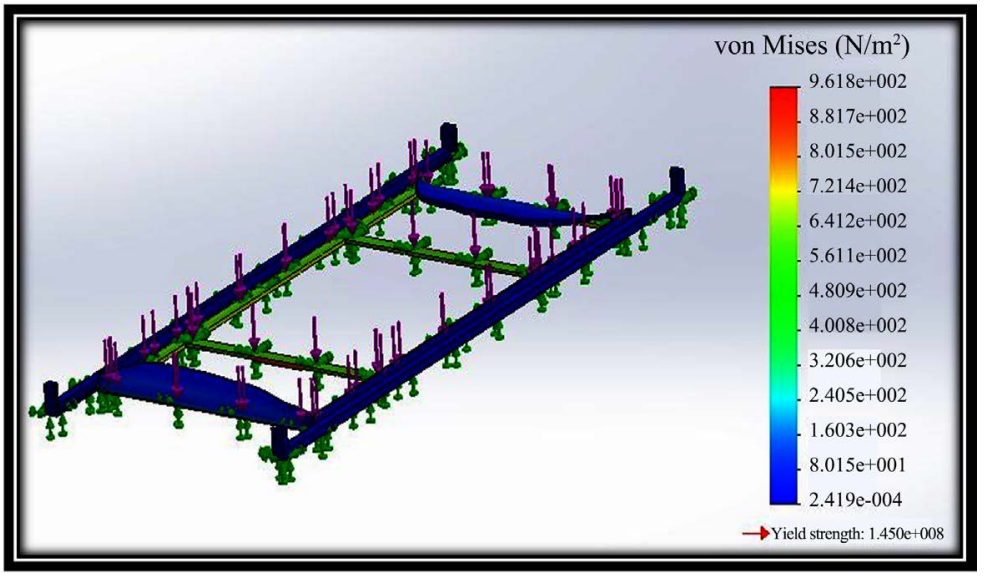

Figure 9. Stress analysis for the main frame carrying the PV and cleaning system.

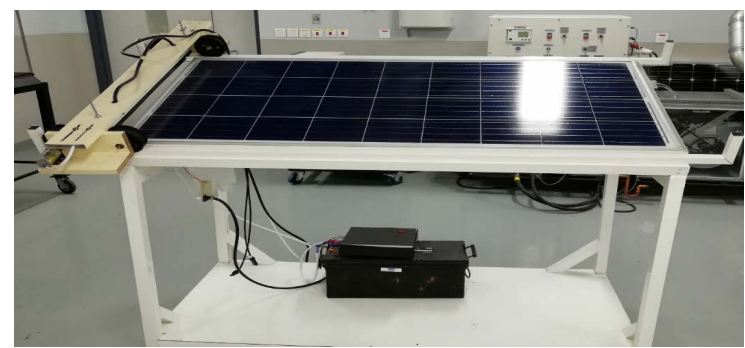

Figure 10. Actual cleaning system installed on the PV panel with the other accessories. 


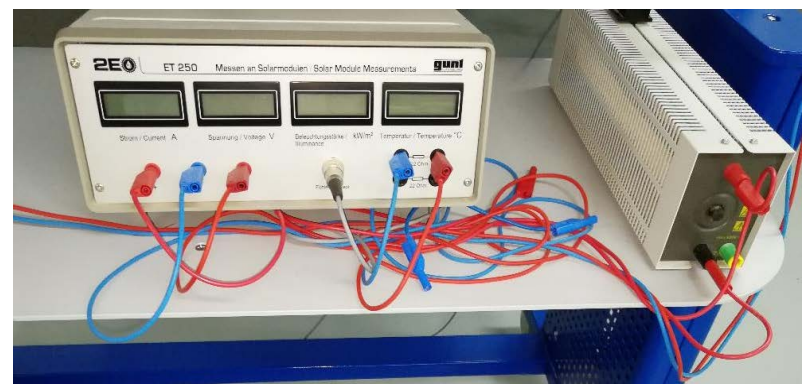

Figure 11. The ET measuring unit for PV output.

Table 2. Results obtained for clean and dusty panel at radiation intensity of $805 \mathrm{~W} / \mathrm{m}^{2}$.

\begin{tabular}{cccccc}
\hline$U($ Volt $)$ & $I(\mathrm{Amp})$ & $P(\mathrm{~W})$ & $U($ Volt $)$ & $I(\mathrm{Amp})$ & $P(\mathrm{~W})$ \\
\hline 0.00 & 3.42 & 0.00 & 0.00 & 2.6 & 0.00 \\
13.58 & 3.28 & 44.62 & 11.31 & 2.5 & 28.92 \\
19.88 & 3.14 & 62.48 & 16.56 & 2.4 & 40.49 \\
23.66 & 3.00 & 70.98 & 19.71 & 2.3 & 46.005 \\
32.9 & 2.85 & 94.00 & 27.41 & 2.2 & 60.92 \\
39.76 & 2.71 & 107.92 & 33.13 & 2.1 & 69.94 \\
43.96 & 2.57 & 113.04 & 36.63 & 2 & 73.26 \\
45.36 & 2.42 & 110.16 & 37.80 & 1.8 & 71.40 \\
45.76 & 2.28 & 104.59 & 38.13 & 1.7 & 67.79 \\
46.34 & 2.14 & 99.3 & 38.61 & 1.6 & 64.36 \\
46.76 & 2.00 & 93.52 & 38.96 & 1.5 & 60.61 \\
47.32 & 1.85 & 87.88 & 39.43 & 1.4 & 56.95 \\
47.6 & 1.71 & 81.6 & 39.66 & 1.33 & 52.88 \\
47.88 & 1.57 & 75.24 & 39.90 & 1.2 & 48.76 \\
48.30 & 1.42 & 69.00 & 40.25 & 1.1 & 44.72 \\
49.28 & 1.00 & 49.28 & 41.06 & 0.7 & 31.94 \\
49.42 & 0.85 & 42.36 & 41.18 & 0.6 & 27.45 \\
50.82 & 0.00 & 0.00 & 42.35 & 0.00 & 0.00 \\
\hline & & & & &
\end{tabular}

As mentioned before the measured data used to draw the I-U characteristic curves shown in Figure 12 for the solar radiation intensity of $805 \mathrm{~W} / \mathrm{m}^{2}$ where the maximum output power $113.04 \mathrm{~W}$ for the cleaning panel and $73.26 \mathrm{~W}$ for the dusty panel. The characteristic U-I curve for the solar radiation intensity of $460 \mathrm{~W} / \mathrm{m}^{2}$ shown in Figure 13 where the maximum output power $59.346 \mathrm{~W}$ for the cleaning panel and $34.4 \mathrm{~W}$ for the dusty panel. From these two figures one can recognize the effect of dust and other dirt on the performance of the module where the significant reduction in the system output can be observed.

The system efficiency has been examined for clean and dusty modules and can be estimated from the input solar radiation $\left(P_{r a d}\right)$ and the output as electrical power $P_{e l}$ 


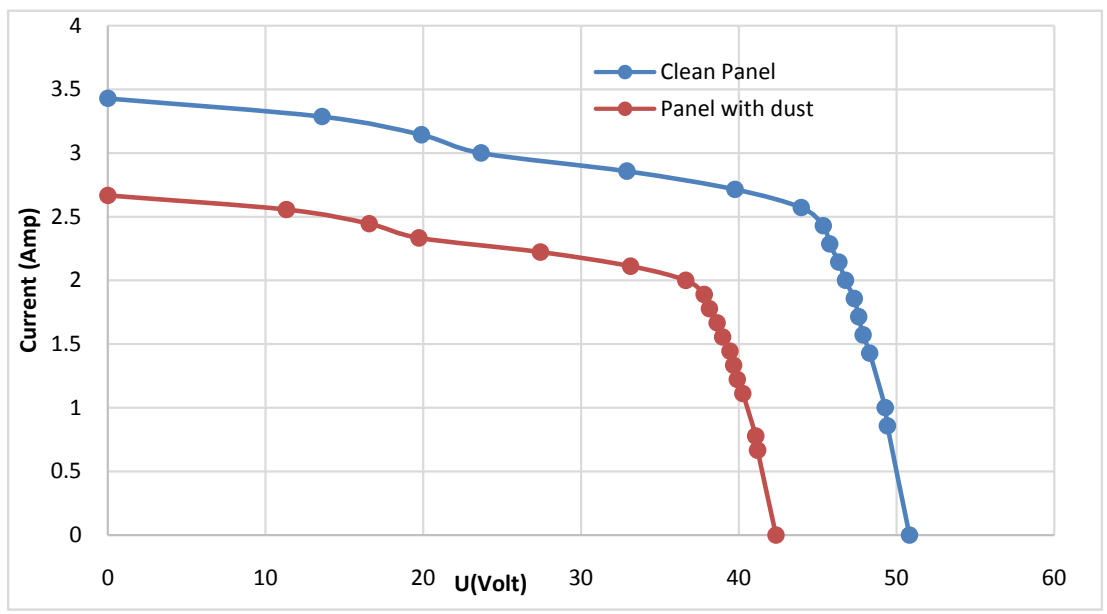

Figure 12. Measured I-U characteristics input power of $805 \mathrm{~W} / \mathrm{m}^{2}$.

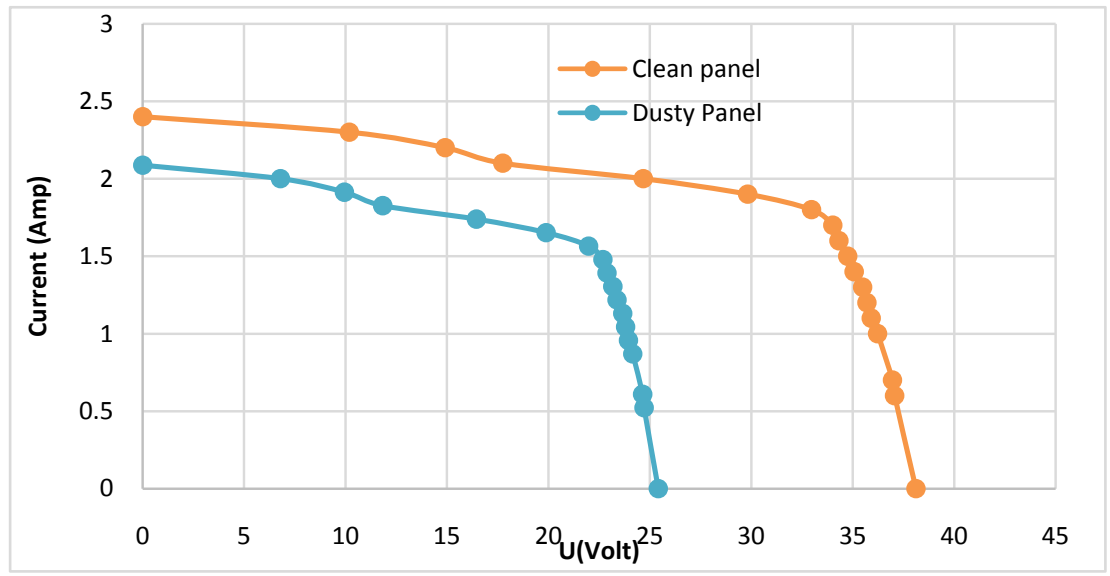

Figure 13. Measured I-U characteristics at input power of $460 \mathrm{~W} / \mathrm{m}^{2}$.

$$
\begin{gathered}
P_{e l}=U I \\
\eta=\frac{P_{e l}}{P_{r a d}} \quad[17]
\end{gathered}
$$

The measured solar radiation intensity is $805 \mathrm{~W} / \mathrm{m}^{2}$ at $12: 00$ noon $\eta=\frac{113.04}{805 \times 1.0186}=13.78 \%$ for clean PV Panel. $\eta=\frac{73.26}{805 \times 1.0186}=9 \%$ for the dusty PV Panel.

The reduction in the efficiency $(E)$ between clean and dusty module as a result of dust effect is

$$
E=\frac{13.78-9}{13.78}=34.68 \%
$$

For the solar radiation intensity of $460 \mathrm{~W} / \mathrm{m}^{2}$ for the clean and dusty surfaces as:

$$
\eta=\frac{59.346}{460 \times 1.0186}=12.6 \% \text { for clean PV Panel. }
$$


$\eta=\frac{34.403}{805 \times 1.0186}=7.3 \%$ for dusty PV Panel.

where the reduction in the efficiency $(E)$ as a result of dust effect

$$
E=\frac{12.66-7.3}{12.66}=42.33 \%
$$

From the reported results above, it can be seen that the dust and deposits accumulation has a significant effect on the performance of the PV module and thus reduce the output power that can be generated from the system. The reduction in system efficiency varied between $35 \%$ to $42 \%$ and it depends on the solar radiation and the thickness of dust layer as well as the location and outside conditions such as dry bulb temperature, humidity, wind velocity and Panel location.

\section{Conclusions}

Design and fabrication of a cleaning system powered by solar energy integrated with PV panel has been carried out in this investigation. The system will help to maintain the efficiency of PV cells by cleaning the dust film and other deposits on the panel surface that could block the sunrays from the semiconductor material within the PV panel. The system is designed to work periodically, and controlled by a mechanism that works automatically under all conditions. The system is applicable for households, companies, and can be used easily for any PV arrays. The cleaning system checked from strength point of view for all structure such as frame, wheels, coupling and connected link and found to be safe and stable. The system performance for both cleaning and dusty panels has been evaluated and it was found that the efficiency for the cleaning system is $13.78 \%$ for cleaning module and $9 \%$ for dusty surface panel with reduction of $34.68 \%$ at the input power of $805 \mathrm{~W} / \mathrm{m}^{2}$ whereas the dust accumulation will reduce the efficiency $42 \%$ at the input power of $460 \mathrm{~W} / \mathrm{m}^{2}$. It can be concluded that this design is a promising method to enhance the PV module performance in Median areas where the weather can be classified as dusty and the pollutants are increased day by day as a results of smokes, industrial work and new building construction.

\section{Conflicts of Interest}

The authors declare no conflicts of interest regarding the publication of this paper.

\section{References}

[1] Zafar, S. (2019) Solar Energy in Saudi Arabia: Perspectives. Echoing Sustainability in MENA “Middle East, Renewable Energy, Solar Energy, 2019”.

[2] NREL/Sandia/Sunspec Alliance SuNLaMP PV O\&M Working Group (2016) Best Practices in PV System Operations and Maintenance. National Laboratory of the U.S. Department of Energy. 
[3] Mohamed, A. and Hasan, A. (2012) Effect of Dust Accumulation on Performance of Photovoltaic Solar Modules in Sahara Environment. Journal of Basic and Applied Scientific Research, 2, 11030-11036.

[4] Does United Arab Emirates Really Have Dirties Air World Dust Up. https://www.economist.com/news/middle-east-and-africa/21657805

[5] Mani, M. and Pillai, R. (2010) Impact of Dust on Solar Photovoltaic (PV) Performance: Research Status, Challenges and Recommendations. Renewable and Sustainable Energy Reviews, 14, 3124-313. https://doi.org/10.1016/j.rser.2010.07.065

[6] Ibrahim, A. (2011) Effect of Shadow and Dust on the Performance of Silicon Solar Cell. Journal of Basic and Applied Scientific Research, 1, 222-230.

[7] Goossens, D. and Kerchaever, E.V. (1999) Aeolian Dust Deposition on Photovoltaic Solar Cells: The Effect of Wind Velocity and Airborne Dust Concentration on Cell Performance. Solar Energy, 66, 277-289. https://doi.org/10.1016/S0038-092X(99)00028-6

[8] Plazaa, D.M., Abdallah, A., Figgisa, B.W. and Mirza, T. (2015) Performance Improvement Techniques for Photovoltaic Systems in Qatar: Results of First Year of Outdoor Exposure. Energy Procedia, 77, 386-396.

https://doi.org/10.1016/j.egypro.2015.07.054

[9] Sharma, R., Wyatt, C.A., Zhang, J., Calle, C.I., Mardesich, N. and Mazumder, M.A.Q. (2009) Experimental Evaluation and Analysis of Electrodynamic Screen as Dust Mitigation Technology for Future Mars Missions. IEEE Transactions on Industry Applications, 45, 591-596. https://doi.org/10.1109/TIA.2009.2013542

[10] Sayyah, A., Horenstein, M.N. and Mazumder, M.K. (2013) Mitigation of Soiling Losses in Concentrating Solar Collectors. IEEE 39 th Photovoltaic Specialists Conference, Tampa, 16-21 June 2013. https://doi.org/10.1109/PVSC.2013.6744194

[11] Burton, D. and King, B.H. (2014) Photovoltaics Spectral Sensitivity of Simulated Photovoltaic Module Soiling for a Variety of Synthesized Soil Types. IEEE Journal of Photovoltaics, 4, 890-898. https://doi.org/10.1109/JPHOTOV.2014.2301895

[12] Verma, A. and Singhal, S. (2015) Solar PV Performance Parameter and Recommendation for Optimization of Performance in Large Scale Grid Connected Solar PV Plant. Journal of Energy and Power Sources, 2, 40-53.

[13] Sulaiman, S.A., Hussain, H.H., Nikleh, N.S. and Razali, M.S. (2011) Effects of Dust on the Performance of PV Panels. International Journal of Mechanical and Mechatronics Engineering, 5, 2021-2026.

[14] Ali, H.M., Zafara, M.A., Bashir, M.A., Nasjr, M.A., Ali, M. and Siddic, Ay.M. (2017) Effect of Dust Deposition on the Performance of Photovoltaic Modules in Texila, Pakistan. Thermal Science, 21, 915-923. https://doi.org/10.2298/TSCI140515046A

[15] Latitude and Longitude Organization. http://latitudelongitude.org/sa/medina

[16] Budynas, R.G. and Nisbett, J.K. (2010) Shigly's Mechanical Engineering Design. 10th Edition, McGraw Hill Education, New York.

[17] Jäger, K., Isabella, O., Smets, A.H.M., Swaaij, R.A. and Zeman, M. (2014) Solar Energy Fundamentals, Technology, and Systems. Delft University of Technology, Delft. 